\title{
Produção de moranga irrigada com esgoto doméstico tratado
}

\author{
Pedro C. P. de Oliveira', Thomas V. Gloaguen', \\ Roberta A. B. Gonçalves ${ }^{3}$ \& Dionei L. Santos ${ }^{4}$
}

\begin{abstract}
RESUMO
Objetivou-se, neste trabalho, avaliar a produção de moranga (Cucurbita maxima Duch. Cv Coroa IAC) irrigada com esgoto doméstico tratado. O delineamento experimental foi em blocos casualizados com cinco tratamentos e quatro repetições. Os tratamentos se constituíram de : $\mathrm{T}_{1}$ - irrigação com lâmina de $150 \%$ da demanda hídrica da cultura; $\mathrm{T}_{2}$ - irrigação com lâmina de $150 \%$ + adição de $\mathrm{CaSO}_{4}$ no solo; $\mathrm{T}_{3}$ - irrigação com lâmina de $100 \%$ da demanda hídrica da cultura; $\mathrm{T}_{4}$ - irrigação com lâmina de $100 \%+$ adição de $\mathrm{CaSO}_{4}$ no solo e $\mathrm{T}_{5}$ - tratamento testemunha (sem irrigação). Foram avaliados a produtividade da cultura, o peso e o número de frutos, suas características físico-químicas ( $\mathrm{pH}$, acidez total, sólidos solúveis, açúcares totais, açúcares redutores e açúcares não redutores) e potencial de contaminação por agentes patogênicos na água. Foi identificada diferença significativa entre o tratamento testemunha e os demais tratamentos em relação à produção, produtividade e número de frutos. As características físicoquímicas apresentaram valores similares em todos os tratamentos. Foi registrada a presença de coliformes termo tolerantes somente na superfície externa dos frutos porém em níveis abaixo dos padrões mínimos estabelecidos pelas normas sanitárias.
\end{abstract}

Palavras-chave: reúso de água, irrigação, produtividade agrícola, aspectos sanitários

\section{Pumpkin yield irrigated with treated domestic wastewater}

\begin{abstract}
The objective of this study was to evaluate the yield of pumpkin (Cucurbita maxima Duch. Coroa IAC) irrigated with treated domestic wastewater. The study was conducted in a completely randomized design with five treatments and four replications. The treatments were: $T_{1}$ - irrigation depth of $150 \%$ of crop water demand; $\mathrm{T}_{2}$ - irrigation depth of $150 \%$ of crop water demand with application of $\mathrm{CaSO}_{4}$ in soil; $\mathrm{T}_{3}$ - irrigation depth of $100 \%$ of crop water demand; $T_{4}$ - irrigation depth of $100 \%$ of crop water demand with application of $\mathrm{CaSO}_{4}$ in soil and $\mathrm{T}_{5}$ - control (without irrigation). The parameters evaluated were: crop yield, weight and number of fruits, their physico-chemical characteristics and potential contamination by pathogens in water. Significant differences in productivity, yield and number of fruits were identified between the control and all other treatments. The physico-chemical characteristics were similar in all treatments. Thermo tolerant coliforms were detected only on the surface of the fruit, but at levels below the minimum standards established by the sanitary legislation.
\end{abstract}

Key words: water reuse, irrigation, agricultural productivity, sanitary aspects 


\section{INTRODUÇÃO}

Existe uma crescente competição pelo uso da água entre diversos setores da sociedade sendo o uso da água na agricultura o de maior demanda; entretanto apresenta, especialmente nos países mais pobres, claros indícios de uma prática insustentável (Christofidis, 2006). Desta forma, torna-se conveniente uma realocação dos recursos hídricos usados na agricultura para outros setores.

Assim, cresce em todo o mundo a consciência em torno da importância do uso racional, da necessidade de controle de perdas e desperdícios e do reúso da água incluindo a utilização de esgotos sanitários com seus inegáveis atrativos (Florêncio et al., 2006).

O uso de águas de esgotos tratados é de grande potencial para a agricultura sobretudo em regiões áridas e semiáridas (Andrade et al., 2005) uma vez que esta prática se constitui em uma fonte de suprimento de recursos hídricos para as culturas agrícolas em região onde a água é escassa (Mota et al., 1997) disponibilizando a água potável para outros fins. Além disto, o reúso evita o lançamento de efluentes de estações de tratamento de esgoto em corpos de água, em sua maioria intermitente e aproveita os nutrientes contidos no esgoto doméstico tratado como fonte de fertilizante para as culturas irrigadas ao invés de potencializar a eutrofização dos corpos hídricos. Ainda segundo Bouwer \& Chaney (1974) a irrigação com esgoto tratado desde que adequadamente conduzida, também poderá funcionar como forma de tratamento adicional dos efluentes provenientes do tratamento de esgoto por meio da filtração natural proporcionada pelo sistema solo-planta.

Do ponto de vista da nutrição vegetal, vários estudos indicam efeitos positivos da irrigação com esgotos na produção e na produtividade das culturas (Al-Nakshabandi et al., 1997; Johns \& McConchie, 1994; Hespanhol, 2003). Por outro lado, podem apresentar aspectos negativos que vão desde modificações nas propriedades químicas e físicas do solo como riscos de contaminação por agentes patogênicos (Emongor et al., 2005).

A moranga, também conhecida como abóbora jerimum, é uma planta rasteira com folhas verde arredondadas e desprovidas de manchas, possuindo pedúnculo cilíndrico corticoso que não apresenta dilatação na região de inserção do fruto; sua boa adaptação a regiões quentes e semiáridas e a importância econômica e alimentar motivaram a seleção da cultura para este trabalho.

O objetivo principal deste trabalho foi avaliar a produção da moranga irrigada com esgoto tratado, além da qualidade físico-química e sanitária dos frutos aplicando-se lâminas de irrigação para atendimento de 100 e $150 \%$ da demanda hídrica da cultura, aplicando-se cálcio como competidor do sódio presente no esgoto.

\section{Material e Métodos}

Este trabalho foi desenvolvido no município de Cravolândia, $\mathrm{BA}$, em área vizinha à estação de tratamento de esgoto doméstico operada pela EMBASA (Empresa Baiana de Águas e Saneamento) e pertencente à Fazenda Estados. O município está localizado a $477 \mathrm{~m}$ de altitude, coordenadas geográficas $13^{\circ} 21^{\prime} 32^{\prime \prime}$ latitude Sul e 39 48' 54" longitude oeste. Segundo classificação original de Köppen, o município apresenta clima do tipo Aw (quente e úmido com chuvas de verão), porém, de acordo com a Portaria Interministerial $n^{\circ} 1$ de 09/03/2005, sua área foi inserida no semiárido baiano tomando-se por base critérios atualizados de precipitação pluviométrica média anual (menor que $800 \mathrm{~mm}$ ), índice de aridez (até 0,5 ) e risco de seca (maior que 60\%). As precipitações e as temperaturas médias anuais são, respectivamente, de $800 \mathrm{~mm} \mathrm{e} 22{ }^{\circ} \mathrm{C}$. A evapotranspiração anual da região ultrapassa frequentemente os $800 \mathrm{~mm}$ enquanto a radiação solar global diária é de $18 \mathrm{MJ}$ $\mathrm{m}^{-2} \mathrm{~d}^{-1}$, para uma insolação diária média de $6 \mathrm{~h}$.

O delineamento experimental foi em blocos casualizados, com cinco tratamentos e quatro repetições. Os tratamentos se constituíram de: $\mathrm{T}_{1}$ - irrigação com lâmina de $150 \%$ da demanda hídrica da cultura; $\mathrm{T}_{2}$ - irrigação com lâmina de $150 \%$ + adição de $\mathrm{CaSO}_{4}$ no solo; $\mathrm{T}_{3}$ - irrigação com lâmina de $100 \%$ da demanda hídrica da cultura; $\mathrm{T}_{4}$ - irrigação com lâmina de $100 \%$ + adição de $\mathrm{CaSO}_{4}$ no solo e $\mathrm{T}_{5}$ - tratamento testemunha (sem irrigação).

A adição de cálcio ao solo objetivou promover a competição deste elemento com o sódio, evitando ou minimizando desta forma os efeitos deste último na dispersão das argilas. Com relação às lâminas aplicadas de $150 \%$ da demanda hídrica, seu principal propósito foi promover a lixiviação dos sais do esgoto e do $\mathrm{CaSO}_{4}$ adicionado.

As sementes de moranga coroa IAC (Cucurbita máxima Duch.) no total de três, foram dispostas a $2 \mathrm{~cm}$ de profundidade em covas abertas nas dimensões de 0,4 x 0,4 m, previamente adubadas e cujo espaçamento foi de 3,0 x 2,5 m. Mantiveram-se duas linhas de três plantas por parcela totalizando seis plantas na área útil; após a germinação foi efetuado o desbaste deixandose duas plantas por cova; a área experimental totalizou cerca de $900 \mathrm{~m}^{2}$.

Foram realizadas todas as práticas culturais e fitossanitárias preconizadas ou que se fizeram necessárias. Registrou-se a presença de insetos praga e doenças de natureza fúngica durante o ciclo da cultura, tendo sido utilizados produtos à base de óleo de nim (Azadirachta indica) como alternativa de controle.

O sistema de irrigação por gotejamento foi utilizado com uma linha de mangueira por fileira de plantas em que foram inseridos gotejadores autocompensantes espaçados cerca de $0,86 \mathrm{~m}$, em uma relação de três gotejadores por planta com vazão máxima de $4 \mathrm{~L} \mathrm{~h}^{-1}$. A estimativa da lâmina a ser aplicada foi feita a partir do uso da equação de Blaney Cridlle utilizando-se dados climáticos (temperatura média mensal) de estações meteorológicas da região tendo-se adotado um turno de rega de 1 dia. Durante o período, além do esgoto aplicado aos respectivos tratamentos, foram registradas precipitações pluviométricas num total de $204,5 \mathrm{~mm}$.

A fonte de água utilizada na irrigação foi o efluente advindo diretamente da última lagoa da estação de tratamento de esgoto do município de Cravolândia. A estação é composta por cinco lagoas facultativas e aeróbicas em série e uma sexta lagoa de maturação, obtendo-se a remoção completa de ovos de helmintos; seus principais constituintes analisados se encontram relacionados na Tabela 1 . 
Tabela 1. Características químicas e microbiológicas médias do esgoto tratado da estação de tratamento de Cravolândia

\begin{tabular}{lcc}
\hline \multicolumn{1}{c}{ Parâmetro } & Unidade & Valor \\
Acalinidade & $\mathrm{mg} \mathrm{L}^{-1}$ & 115,65 \\
Amônia & $\mathrm{mg} \mathrm{L}^{-1}$ & 0,40 \\
Cálcio & $\mathrm{mg} \mathrm{L}^{-1}$ & 3,00 \\
CE & $\mathrm{dS} \mathrm{m}^{-1}$ & 1,42 \\
Cloreto & $\mathrm{mg} \mathrm{L}^{-1}$ & 5,00 \\
Magnésio & $\mathrm{mg} \mathrm{L}^{-1}$ & 0,40 \\
Nitrato & $\mathrm{mg} \mathrm{L}^{-1}$ & 2,10 \\
Potássio & $\mathrm{mg} \mathrm{L}^{-1}$ & 5,00 \\
pH & & 7,98 \\
RAS & $\mathrm{m} \mathrm{molL}^{-1 / 2}$ & 6,20 \\
Sódio & $\mathrm{mg} \mathrm{L}^{-1}$ & 25,00 \\
Coliformes termotolerantes & NMP 100 mL & $9,4 \times 10^{-1}$ \\
Ovos de helmintos & Ovo L & ausente \\
\hline
\end{tabular}

CE - Condutividade elétrica; RAS - Razão de adsorção de sódio; NMP - Número Mais Provável

Antes da implantação do experimento realizou-se amostragem de solo para fins de análise química a partir de amostras coletadas de 0 a $20 \mathrm{~cm}$ de profundidade; além disto foram determinados, em laboratório, os valores de densidade aparente, umidade na capacidade de campo e no ponto de murchamento (Tabela 2). A análise granulométrica do solo apresentou os valores de $80,2,1,5$ e $18,3 \%$ respectivamente para areia, silte e argila, classificando-o como franco-arenoso.

As adubações de fundação e cobertura foram efetuadas de acordo com os resultados das análises levando-se em consideração, também, parâmetros preconizados por Ramos et al. (2010). Foram utilizados N, P e K nas dosagens respectivas de 60,80 e $30 \mathrm{~kg} \mathrm{ha}^{-1}$, sendo P e K no plantio e $\mathrm{N}$ em cobertura. As aplicações de cálcio nos tratamentos $\mathrm{T}_{2}$ e $\mathrm{T}_{4}$ foram efetuadas quinzenalmente por cobertura, no total de $6 \mathrm{~g}$, junto aos gotejadores correspondentes aos respectivos tratamentos.

Amostragens de solo até $40 \mathrm{~cm}$ de profundidade em cada parcela, também foram realizadas após o experimento, cuja duração aproximada foi de quatro meses. As amostras foram retiradas a $20 \mathrm{~cm}$ de distância dos gotejadores. Analisaram-se: $\mathrm{pH}, \mathrm{CE}, \mathrm{K}, \mathrm{Ca}$ e Na e, posteriormente, efetuou-se o cálculo do PST, conforme recomendações de Raij et al. (2001). A CE foi definida través de leitura direta com condutivímetro, a partir da extração das pastas de saturação do solo.

A cultura foi plantada em 1 de fevereiro de 2011 e a colheita efetuada nos dias 4 e 7 de junho. Todos os frutos colhidos foram registrados e pesados sendo identificados por cada parcela e tratamento.

O material para amostragem microbiológica (frutos) foi analisado após $48 \mathrm{~h}$. A polpa e a casca foram picadas (separadamente) e diluídas, partindo da adição de $10 \mathrm{~g}$ de fruto em $90 \mathrm{~mL}$ de solução salina e agitada mecanicamente durante 20 min; em seguida, foi diluída em série ou não, conforme a necessidade. As alíquotas foram inoculadas em Caldo EC e incubadas a $45^{\circ} \mathrm{C}$ em banho-maria, por $48 \mathrm{~h}$. A quantificação de coliformes termo tolerantes foi realizada através da técnica de fermentação em tubos múltiplos e expressa pelo Número Mais Provável (NMP) $100 \mathrm{~mL}^{-1}$ com 95\% de confiança (APHA, 2012).

As análises de natureza físico-química de 20 frutos representando cada tratamento, foram realizadas no Laboratório de Tecnologia de Alimentos da Universidade Estadual de Feira de Santana. Os procedimentos seguiram metodologias de acordo com Zenebon et al. (2008), sendo: leitura direta em potenciômetro, para determinação de $\mathrm{pH}$; medida em graus brix feita diretamente no refratômetro visando determinar sólidos solúveis e titulação potenciométrica para determinação da acidez. As determinações de açúcares totais, redutores e não redutores foram efetuadas a partir do método colorimétrico do 3,5-dinitrosalicilico (DNS) descrito por Miller (1959).

Os dados referentes a peso e número de frutos, produção e produtividade tal como os parâmetros físico-químicos, foram submetidos à análise de variância utilizando-se o programa Sisvar. Os resultados foram comparados entre si usando-se o teste de Tukey a nível de 0,05 de probabilidade.

\section{Resultados E Discussão}

Foram registradas diferenças significativas entre as culturas irrigadas e não irrigadas (testemunha) em relação a três das variáveis relacionadas na Tabela 3 .

Tabela 3. Dados estatísticos de produção média, produtividade, peso e número médio de frutos

\begin{tabular}{lcccc}
\hline Tratamentos & $\begin{array}{c}\text { Produção } \\
\text { média } \\
(\mathbf{k g})\end{array}$ & $\begin{array}{c}\text { Produtividade } \\
\mathbf{( t ~ h a - 1}^{-1}\end{array}$ & $\begin{array}{c}\text { Peso } \\
\text { fruto } \\
(\mathbf{k g})\end{array}$ & $\begin{array}{c}\mathbf{N}^{0} \\
\text { frutos }\end{array}$ \\
T1 $(150 \%)$ & $124,6 \mathrm{a}$ & $27,7 \mathrm{a}$ & $3,2 \mathrm{a}$ & $39,3 \mathrm{a}$ \\
T2 $(150 \%+\mathrm{Ca})$ & $118,7 \mathrm{a}$ & $26,4 \mathrm{a}$ & $2,9 \mathrm{a}$ & $41,0 \mathrm{a}$ \\
T3 $(100 \%)$ & $116,3 \mathrm{a}$ & $25,8 \mathrm{a}$ & $2,6 \mathrm{a}$ & $45,0 \mathrm{a}$ \\
T4 $(100 \%+\mathrm{Ca})$ & $120,4 \mathrm{a}$ & $26,7 \mathrm{a}$ & $2,8 \mathrm{a}$ & $43,2 \mathrm{a}$ \\
T5 (Testemunha & $57,3 \mathrm{~b}$ & $12,7 \mathrm{~b}$ & $2,7 \mathrm{a}$ & $21,0 \mathrm{~b}$ \\
\hline CV & 9,47 & 9,45 & 13,67 & 15,55 \\
Dms & 22,90 & 5,10 & 0,90 & 13,30 \\
Valor de F & $30,74^{*}$ & $30,81^{*}$ & $1,16 \mathrm{~ns}$ & $10,83^{*}$ \\
\hline
\end{tabular}

Médias seguidas da mesma letra não diferem entre si pelo teste de Tukey a nível de 0,05 de probabilidade

* e ns - significativo a 0,01 e não significativo, respectivamente

Foram registradas diferenças estatísticas entre os tratamentos irrigados e o tratamento sem irrigação $\left(\mathrm{T}_{5}\right)$ com relação a produção média, com a máxima produção $(124,6 \mathrm{~kg})$ obtida pelo tratamento $\mathrm{T}_{1}$ (Tabela 3 ). Os melhores resultados mostrados pelos tratamentos irrigados quando comparados com o tratamento testemunha, dentre outros aspectos, estão relacionados, em maior grau, com a maior disponibilidade de água proporcionada pela irrigação. É provável que, em culturas de ciclo mais longo, as diferenças resultantes do efeito das lâminas de irrigação tenderiam a acentuar-se e, desta forma, atingir grau de significância.

Tabela 2. Resultados de análise físico-hídrica e de fertilidade do solo antes do experimento

\begin{tabular}{|c|c|c|c|c|c|c|c|c|c|c|c|c|c|c|c|}
\hline \multirow{2}{*}{$\begin{array}{c}\mathrm{pH} \\
\text { (água) }\end{array}$} & K & $\mathrm{Ca}$ & $\mathrm{Mg}$ & $\mathrm{Ca}+\mathrm{Mg}$ & Al & $\mathrm{Na}$ & $\mathrm{H}+\mathrm{Al}$ & $\mathbf{S}$ & CTC & $\mathbf{V}$ & PST & \multirow{2}{*}{$\begin{array}{c}P \\
\mathrm{mg} \mathrm{dm}\end{array}$} & $\theta$ CCC & $\theta \mathrm{pm}$ & \multirow{3}{*}{$\begin{array}{c}\text { Dap } \\
\mathbf{k g ~ d m}^{-3} \\
1,57\end{array}$} \\
\hline & \multicolumn{9}{|c|}{$\mathrm{cmol}_{\mathrm{c}} \mathrm{dm}^{-3}$} & \multicolumn{2}{|c|}{$\%$} & & \multicolumn{2}{|c|}{$\%$} & \\
\hline 5,4 & 0,31 & 2,2 & 0,0 & 2,2 & 0,0 & 0,28 & 1,76 & 2,79 & 4,55 & 61 & 6,2 & 7.0 & 15,31 & 8,15 & \\
\hline
\end{tabular}

CTC - Capacidade de troca de cátions; S - Soma de bases; V - Percentual de saturação de bases; PST - Percentual de sódio trocável; $\theta$ cc - Umidade na capacidade de campo; $\theta$ pm - Umidade no ponto de murchamento; Dap - Densidade aparente do solo 
Os resultados obtidos estão de acordo com os observados por Azevedo \& Oliveira (2005) que, utilizando esgoto tratado na irrigação de pepino, observaram maior produção média por planta em relação ao tratamento testemunha (água de abastecimento tratada). Referidos autores constataram valores mais elevados em determinadas variáveis químicas do solo, enfatizando uma possível influência nos resultados de produção das plantas. Também Mota et al. (1997) constataram, avaliando o desempenho de culturas sob irrigação com esgoto tratado, produções superiores de grãos e caroço respectivamente, para sorgo e algodão porém, os resultados discordaram daqueles obtidos por Sousa et al. (2006) que, irrigando pimentão com esgoto proveniente de lagoa de polimento, registraram baixa produtividade da cultura, relacionando tal fato aos elevados valores de $\mathrm{pH}$ registrados no esgoto e sua consequente influência sobre o solo, reduzindo a disponibilidade de nutrientes para a cultura.

Segundo Ayers \& Westcot (1999) as diretrizes para se avaliar a qualidade da água de irrigação se referem sobretudo aos efeitos a longo prazo da qualidade da água sobre a produção das culturas, nas condições de solo e manejo agrícola. Ainda de acordo com os limites estabelecidos pelos autores citados, o valor médio do $\mathrm{pH}$ do esgoto tratado se mantém na faixa normal de variação; já os valores de CE e RAS quanto ao grau de restrição para uso, classificam o esgoto tratado como de restrição ligeira a moderada (Tabela 1).

Por outro lado e se considerando apenas os tratamentos irrigados, a cultura irrigada com $100 \%$ da demanda hídrica $\left(\mathrm{T}_{3}\right)$ apresentou os menores desempenhos absolutos em termos de produção média observando-se, neste tratamento, os maiores valores de PST (percentual de sódio trocável), CE (condutividade elétrica) e sódio, o que poderá configurar a influência dessas variáveis nos resultados após maiores períodos de uso (Tabela 4).

Tabela 4. Resultado de análise química do solo na profundidade de $0-40 \mathrm{~cm}$ após o experimento

\begin{tabular}{|c|c|c|c|c|c|c|}
\hline \multirow{2}{*}{ Tratamento } & \multirow{2}{*}{$\mathrm{pH}$} & $\mathrm{Na}$ & K & $\mathrm{Ca}$ & \multirow{2}{*}{$\begin{array}{c}\text { CE } \\
d S m^{-1}\end{array}$} & \multirow{2}{*}{$\begin{array}{c}\text { PST } \\
\%\end{array}$} \\
\hline & & \multicolumn{3}{|c|}{$\mathrm{cmol}_{\mathrm{c}} \mathrm{dm}^{-3}$} & & \\
\hline T1 (150\%) & $6,3 \mathrm{a}$ & $0,9 \mathrm{a}$ & $0,4 \mathrm{a}$ & $2,6 \mathrm{a}$ & $0,14 \mathrm{a}$ & $12,8 \mathrm{a}$ \\
\hline $0 \%+\mathrm{Ca})$ & $6,2 \mathrm{a}$ & $1,0 \mathrm{a}$ & $0,4 \mathrm{a}$ & $2,7 \mathrm{a}$ & $0,14 \mathrm{a}$ & $13,0 \mathrm{a}$ \\
\hline T3 (100\%) & $6,3 \mathrm{a}$ & $1,1 \mathrm{a}$ & $0,4 \mathrm{a}$ & $2,3 \mathrm{a}$ & $0,17 \mathrm{a}$ & $15,9 \mathrm{a}$ \\
\hline T4 (10 & $6,0 \mathrm{a}$ & $1,0 \mathrm{a}$ & $0,3 a$ & $2,3 \mathrm{a}$ & $5 \mathrm{a}$ & $14,5 \mathrm{a}$ \\
\hline T5(Testemur & $5,1 \mathrm{~b}$ & $0,3 \mathrm{~b}$ & $0,4 \mathrm{a}$ & $2,5 \mathrm{a}$ & $0,25 b$ & $4,3 \mathrm{~b}$ \\
\hline CV & 3,2 & 10,9 & 7,2 & 12,4 & 10,20 & 14,4 \\
\hline Dms & 0,5 & 0,3 & 0,1 & 0,8 & 0,04 & 5,1 \\
\hline Valor de F & $20,76^{*}$ & $31,54^{*}$ & $1,0 \mathrm{~ns}$ & $1,14 \mathrm{~ns}$ & $21,05^{*}$ & $18,75^{*}$ \\
\hline
\end{tabular}

Médias seguidas da mesma letra não diferem entre si pelo teste de Tukey a nível de 0,05 de probabilidade.

* e ns - significativo a 0,01 e não significativo, respectivamente

A salinidade do solo afeta diretamente o desenvolvimento das plantas (Ayers \& Westcot, 1999). Considerando que os níveis de salinidade do solo (CE) dos tratamentos irrigados estiveram em níveis considerados baixos, inclusive inferiores àqueles registrados para o tratamento testemunha, este menor desempenho pode ser associado mais especificamente ao efeito do sódio representado diretamente pela concentração deste elemento no solo ( $\mathrm{Na}$ em $\mathrm{cmol}_{\mathrm{c}} \mathrm{dm}^{-3}$ e PST). Em referência a este aspecto, Cerqueira et al. (2008) também ressaltaram, citando a salinidade como fator mais limitante ao desenvolvimento e rendimento das culturas, o efeito direto ou indireto da sodicidade salientando que o conjunto de efeitos negativos do sódio pode levar a uma redução na produção das culturas em grau variável.

A produtividade estimada da cultura também apresentou diferenças estatísticas entre os tratamentos irrigados e não irrigados; fato semelhante em relação ao observado para a variável anteriormente analisada destacando-se também o tratamento $\mathrm{T}_{1}$ (irrigado com $150 \%$ da demanda hídrica) com produtividade de 27,7 t ha-1 (Tabela 3 ). A exemplo da produção média, tal fato pode ainda estar relacionado sobretudo ao efeito conjunto da maior disponibilidade de água proporcionada pela irrigação, aliado a outros aspectos favoráveis tais como os resultados de $\mathrm{pH}$ mais elevados e menores valores de $\mathrm{CE}$, ambos apresentando diferenças significativas em relação ao tratamento testemunha (sem irrigação). Reportando-se ao esgoto como fonte de suprimento de nutrientes relacionado à produtividade das culturas, Medeiros et al. (2007) ressaltaram, em experimento com gérbera (Gerbera jamesonii) a água residuária como recurso importante no suprimento de nutrientes $(\mathrm{N}, \mathrm{P}, \mathrm{K})$ e água para a cultura, potencializando a produtividade. Al-Nakshabandi et al. (1997) relataram aumentos na produtividade média da berinjela irrigada com esgoto tratado, relacionando este fato, dentre outros fatores, à pronta disponibilidade de nutrientes proporcionada pelo esgoto tratado.

A importância do esgoto tratado no fornecimento de nutrientes em comparação ao seu fornecimento via adubação mineral é destacada por outros autores, a exemplo de Rebouças et al. (2010) que afirmam que os solos irrigados com esgoto tratado conseguem suprir as necessidades nutricionais do feijão caupi mesmo na ausência de adubação mineral; Santos et al. (2006) que reportam produtividade de quiabo irrigado com esgoto tratado em níveis similares àqueles obtidos com água $\mathrm{e}$ adubo mineral e Costa (2006) que, utilizando esgoto tratado para irrigação de melancia observou que a produtividade da cultura irrigada com esgoto foi equivalente àquela obtida sob condição de irrigação com água de poço mais adubação química.

A maior produtividade obtida pelos tratamentos irrigados com efluente de esgoto está de acordo com os resultados observados por Deon et al. (2010) que, utilizando esgoto tratado na produção de cana de açúcar, verificaram ganhos de produtividade. Contrariando a maior parte dos trabalhos, Peres (2004) não observou ganhos de produtividade comparando meloeiro irrigado com esgoto tratado e água sob os sistemas de sulco e gotejamento, respectivamente. $\mathrm{O}$ autor relatou produtividades médias inferiores aos tratamentos com água limpa.

Em relação ao peso médio dos frutos, não foram registradas diferenças estatísticas entre todos os tratamentos, muito embora os tratamentos irrigados com lâmina de $150 \%$ se tenham destacado em termos absolutos. O peso de frutos constitui-se em parâmetro importante no que se refere ao aspecto comercial dos produtos e está relacionado também ao aspecto nutricional das plantas; neste caso, a maior lâmina de irrigação (150\%) proporcionada pelos tratamentos $\mathrm{T}_{1}$ e $\mathrm{T}_{2}$ pode ter se constituído em fator determinante para maiores valores de peso médio dos frutos, dentre outros, pelo maior aporte de nutrientes viabilizado 
pelo esgoto tratado. Mota et al. (1997) observaram maior peso médio do capulho do algodão irrigado com esgoto tratado em relação àquele irrigado com água.

Sousa et al. (2006) encontraram resultados similares para o peso médio de frutos de pimentão irrigado com esgoto tratado, água de poço artesiano em solo com adubação orgânica e água em solo com vermicomposto. Costa (2006) também não obteve, em experimento com melancia irrigada por gotejamento, diferenças significativas entre os tratamentos no que se refere ao peso dos frutos; entretanto, registrou o maior somatório de peso de frutos para o tratamento irrigado com esgoto tratado mais adubação química.

O peso médio dos frutos foi a única variável analisada que se comportou indiferente à ocorrência ou ausência de diferenças significativas entre os tratamentos irrigados e o tratamento testemunha com relação a alguns dos aspectos químicos do solo observados (Tabela 4). Assim, a variável peso médio de frutos foi o único parâmetro analisado cujo tratamento testemunha $\mathrm{T}_{5}$ obteve estatisticamente um desempenho similar aos outros tratamentos destacando-se, em termos absolutos, mais especificamente em relação ao tratamento $T_{3}$.

Não obstante a limitação hídrica imposta ao tratamento testemunha, reduzindo sua capacidade de produção, produtividade e número médio de frutos em relação aos demais, o resultado obtido quanto ao seu peso médio pode ser explicado também em função da escassez de água no solo que limitou o número de frutos, porém não afetou o peso médio dos mesmos. $\mathrm{O}$ tratamento Testemunha apresentou valores de $\mathrm{pH}, \mathrm{Na}, \mathrm{CE}$ e PST inferiores estatisticamente aos demais tratamentos (Tabela 4) sendo os valores de sódio e PST cerca de três vezes menores que aqueles encontrados nos demais tratamentos.

Em relação à qualidade dos frutos foi colhido um total de 758 frutos, dos quais $95,52 \%$ foram considerados de primeira (peso acima de 1,5 $\mathrm{kg}$ ) enquanto $4,48 \%$ foram considerados de segunda (peso abaixo de $1,5 \mathrm{~kg}$ ). Somente em campo foram observados frutos apresentando podridões; além disto, foi registrado também o ataque de brocas do pedúnculo.

Quanto ao número de frutos os tratamentos irrigados foram superiores estatisticamente em relação ao tratamento testemunha destacando-se o tratamento $\mathrm{T}_{3}$ com média máxima de 45 frutos e o tratamento $T_{1}$ com média mínima de 39,3 frutos (Tabela 3). Os mesmos fatores anteriormente citados podem ser aplicados em conjunto para esta situação, ou seja, a aplicação de diferentes lâminas de esgoto tratado com consequente aporte de nutrientes, bem como as variações químicas apresentadas pelo solo após aplicação atuaram, proporcionando melhores resultados obtidos pelos tratamentos irrigados em referência ao tratamento testemunha.

Medeiros et al. (2007) reportaram, comparando diferentes lâminas de águas residuárias com água de abastecimento no cultivo de gérberas, que o manejo com águas residuárias proporcionou aumento significativo tanto no número de botões florais emitidos quanto no número de flores colhidas quando comparado com o manejo convencional com água de abastecimento.

As análises estatísticas não mostraram diferença significativa entre os tratamentos em relação às variáveis estudadas (Tabela $5)$.

Tais resultados estão de acordo com aqueles encontrados por Costa et al. (2009) que, trabalhando com maracujá fertigado e em sequeiro, não registraram diferenças significativas quanto aos parâmetros $\mathrm{pH}$, acidez total e sólidos solúveis. $\mathrm{O} \mathrm{pH}$ e a acidez total dos frutos foram os parâmetros que apresentaram as menores variações enquanto os resultados do teor de sólidos solúveis, açúcares totais, açúcares redutores e açúcares não redutores mostraram níveis mais elevados de variação principalmente no que se refere aos açúcares. Quanto a este aspecto, Costa et al. (2004) relataram efeitos positivos do aumento da concentração de potássio em solução nutritiva sobre os teores de sólidos solúveis em melão, promovendo sua elevação.

Deon et al. (2010) registraram, em experimento com canade-açúcar irrigada com esgoto tratado, diminuição significativa do teor de sólidos solúveis totais no caldo da cana apenas na primeira soca relacionando tal fato ao maior vigor das plantas irrigadas. Lingle et al. (2000) afirmam que os parâmetros de qualidade do caldo da cana, a exemplo dos sólidos solúveis, só foram afetados pela qualidade da água de irrigação quando a salinidade superou $1,25 \mathrm{dS} \mathrm{m}^{-1}$. Neste experimento o valor máximo de CE obtido foi de $0,25 \mathrm{dS} \mathrm{m}$ m $^{-1}$ no tratamento $\mathrm{T}_{5}$ (testemunha).

Fatores também relacionados à química do solo e nutrição mineral podem exercer influência sobre os parâmetros físicoquímicos dos frutos conforme mostram os trabalhos de Feitosa et al. (2009) que relacionam o potássio às variações ou ausência de variação sobre os parâmetros físico-químicos de frutos de melancia. Esses autores atribuíram parte das variações significativas encontradas nos resultados de $\mathrm{pH}$, sólidos solúveis e acidez total em frutos, às diferenças no teor de potássio em cada tratamento. Neste trabalho todos os tratamentos exibiram baixa concentração de potássio no solo, com o menor valor registrado no tratamento 4 .

Tabela 5. Resultados das análises físico-química dos frutos

\begin{tabular}{|c|c|c|c|c|c|c|}
\hline \multirow{2}{*}{ Tratamento } & \multirow{2}{*}{$\mathrm{pH}$} & \multirow{2}{*}{$\begin{array}{c}\text { Acidez total } \\
\text { (\% } \mathrm{mm}^{-1} \text { Ac. Cítrico) }\end{array}$} & \multirow{2}{*}{$\begin{array}{c}\text { Sólidos solúveis } \\
\text { ( }{ }^{\circ} \text { Brix) }\end{array}$} & \multicolumn{3}{|c|}{ Açucares $\left(\% \mathrm{~mm}^{-1}\right)$} \\
\hline & & & & Totais & Redutores & Não redutores \\
\hline T1 (150\%) & $6,5 \mathrm{a}$ & $0,028 \mathrm{a}$ & $7,0 \mathrm{a}$ & $10,2 \mathrm{a}$ & $3,8 \mathrm{a}$ & $6,4 \mathrm{a}$ \\
\hline T2 $(150 \%+C a)$ & $6,7 \mathrm{a}$ & $0,024 \mathrm{a}$ & $8,0 \mathrm{a}$ & $10,3 \mathrm{a}$ & $3,6 \mathrm{a}$ & $6,6 \mathrm{a}$ \\
\hline T3 (100\%) & $6,6 \mathrm{a}$ & $0,018 \mathrm{a}$ & $7,7 \mathrm{a}$ & $8,1 \mathrm{a}$ & $2,2 \mathrm{a}$ & $5,9 a$ \\
\hline T4 $(100 \%+C a)$ & $6,7 \mathrm{a}$ & $0,075 \mathrm{a}$ & $7,3 \mathrm{a}$ & $10,3 a$ & $2,5 \mathrm{a}$ & $7,8 \mathrm{a}$ \\
\hline T5 (Testemunha) & $6,7 \mathrm{a}$ & $0,012 \mathrm{a}$ & $7,1 \mathrm{a}$ & $7,9 \mathrm{a}$ & $3,0 \mathrm{a}$ & $4,9 \mathrm{a}$ \\
\hline CV & 6,96 & 118,33 & 15,37 & 38,96 & 42,35 & 50,1 \\
\hline $\mathrm{dms}$ & 1,04 & 0,08 & 2,56 & 8,21 & 2,89 & 7,1 \\
\hline Valor de F & $0,16 \mathrm{~ns}$ & $1,82 \mathrm{~ns}$ & $0,58 \mathrm{~ns}$ & $0,47 \mathrm{~ns}$ & $1,08 \mathrm{~ns}$ & $0,46 \mathrm{~ns}$ \\
\hline
\end{tabular}

Médias seguidas da mesma letra não diferem entre si pelo teste de Tukey a nível de 0,05 de probabilidade; ns - Não significativo 
Comparando os tratamentos irrigados os resultados não mostraram diferença significativa entre os respectivos tratamentos com lâminas de $150 \%\left(\mathrm{~T}_{1} \mathrm{e} \mathrm{T}_{2}\right)$ e lâminas de $100 \%$ $\left(\mathrm{T}_{3} \mathrm{e}_{4}\right.$ ). $\mathrm{O}$ tratamento $\mathrm{T}_{2}$ (lâmina de $150 \%$ da demanda hídrica + Ca) destacou-se por apresentar o melhor desempenho médio em relação ao tratamento $\mathrm{T}_{1}$ (lâmina de $150 \%$ da demanda hídrica) no que se refere aos teores de sólidos solúveis, açúcares totais, açúcares não redutores e $\mathrm{pH}$ enquanto o tratamento $\mathrm{T}_{1}$ obteve melhor média em relação ao açúcar redutor; referente à acidez total, ambos apresentaram resultados iguais.

Comparando os tratamentos com lâmina de $100 \%$ da demanda hídrica da cultura, o tratamento $\mathrm{T}_{4}$ (lâmina de $100 \%$ + Ca) obteve o melhor desempenho que o tratamento $\mathrm{T}_{3} \mathrm{em}$ relação aos níveis de açúcares totais, açúcares redutores, açúcares não redutores, acidez total $\mathrm{e} \mathrm{pH}$ enquanto o tratamento $\mathrm{T}_{3}$ (lâmina de $100 \%$ da demanda hídrica) apresentou melhor desempenho em relação ao teor de sólidos solúveis.

As lâminas de irrigação associadas a Ca apresentaram as maiores médias em termos de açúcares totais e açúcares não redutores. Dentre todas as variáveis estudadas o maior valor médio verificado foi obtido pelos tratamentos $\mathrm{T}_{2} \mathrm{e} \mathrm{T}_{4}$ em relação ao teor de açúcares totais enquanto o menor foi registrado para acidez total, no tratamento $\mathrm{T}_{5}$.

Apesar das diferenças em termos absolutos e prevalência de maiores médias em determinados parâmetros, as lâminas de irrigação parecem não ter exercido influência nos resultados apresentados, uma vez que não houve diferença estatística entre os resultados obtidos.

A qualidade sanitária dos produtos obtidos a partir da irrigação com esgoto tratado constitui-se em um dos principais aspectos a serem observados no contexto da produção agrícola. As análises efetuadas nos frutos não registraram a presença de coliformes termotolerantes na polpa, porém foi registrada a presença na superfície externa dos mesmos, com valor máximo de 23 NMP de coliformes por grama em duas amostras (Figura 1).

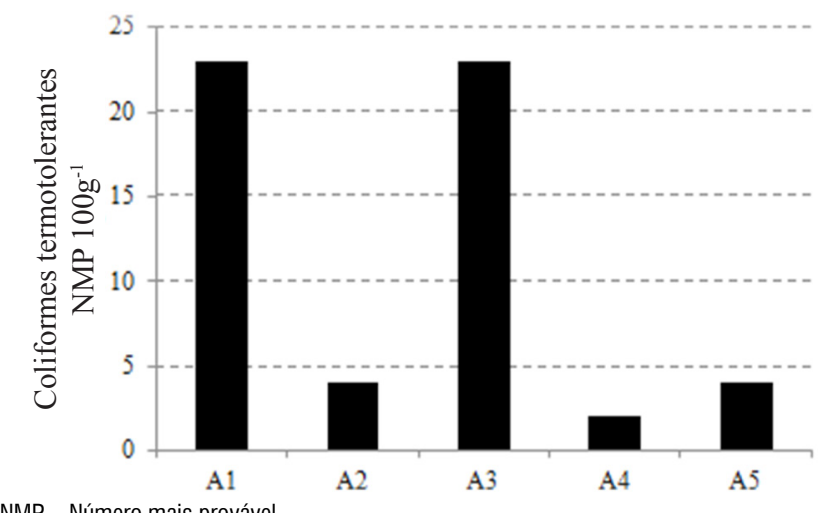

NMP - Número mais provável

Figura 1. Quantidade de coliformes termotolerantes encontrados na casca dos frutos de moranga, referente aos tratamentos irrigados com efluente de esgoto tratado, segundo diferentes amostras (A)

Esses resultados se encontram abaixo do limite máximo admitido pela legislação sanitária para este tipo de cultura (100 coliformes termotolerantes $\mathrm{g}^{-1}$ ).

A partir desta constatação pode-se deduzir que o uso de irrigação localizada permitiu a produção da cultura da moranga com baixo risco de contaminação de frutos por agentes patogênicos nas condições climáticas locais.

Resultados similares foram obtidos por Rego et al. (2005) que registraram a presença de coliformes em níveis abaixo dos limites mínimos estabelecidos irrigando melancia com esgoto tratado sob sistema de irrigação por gotejamento e por sulco. Também Peres (2004) encontrou, em experimento com a cultura do melão irrigado com esgoto tratado e com água, através dos sistemas por sulco e por gotejamento, as mesmas proporções do NMP (número mais provável) de coliformes fecais para ambos os tratamentos e em níveis abaixo dos valores mínimos estabelecidos pela legislação. Al-Nakshabandi et al. (1997) não detectaram, em experimento com a cultura da berinjela, a presença de micro-organismos patogênicos, a exemplo de Salmonella sp e Shigella sp, enquanto a presença de coliformes fecais na casca dos frutos ocorreu em níveis abaixo dos padrões mínimos estabelecidos.

Não obstante recomendações específicas não aconselhando o uso de esgoto tratado para irrigação de hortaliças e frutas rastejantes, os resultados deste trabalho e dos demais citados, vêm mostrando perspectivas bastante favoráveis ao uso do esgoto tratado também neste grupo de culturas alimentares, obtendo-se produtos com qualidade sanitária adequada.

\section{Conclusões}

1. O uso de esgoto tratado promoveu aumento significativo na produção média, número médio de frutos e produtividade estimada da moranga comparando-a com a cultura não irrigada, da ordem de 114,117 e $118 \%$, respectivamente.

2. O uso de lâminas de irrigação com atendimento de 100 ou $150 \%$ da demanda hídrica da cultura da moranga irrigada com esgoto tratado, com ou sem adição de $\mathrm{Ca}$, não promoveu diferenças significativas referentes aos parâmetros avaliados (produção, produtividade, número e peso médio de frutos) entre os tratamentos irrigados.

3. O uso de esgoto tratado não comprometeu a qualidade sanitária dos frutos de moranga.

4. O uso de esgoto tratado não promoveu variações significativas nos parâmetros físico-químicos dos frutos.

\section{Agradecimentos}

Os autores agradecem ao Conselho Nacional de Desenvolvimento Científico e Tecnológico $(\mathrm{CNPq})$ e à Fundação de Amparo à Pesquisa do Estado da Bahia (FAPESB) pelo apoio financeiro a este trabalho, tal como à CAPES, pela concessão de bolsa de estudo.

\section{Literatura Citada}

Al-Nakshabandi, G. A.; Saqqar, M. M.; Shatanawi, M. R.; Fayyad, M.; Al-Horani, H. Some environmental problems associated with the use of treated wastewater for irrigation in Jordan. Agricultural Water Management, v.34, p.81-94, 1997.

Andrade, I.P.; Montenegro, A. A. de A.; Silva, J. A. A. da.; Freire, M. B. G dos S.; Santos, T. E. M. dos. Impacto do reuso de efluentes de esgoto no lixiviado de solos cultivados com milho. Revista Brasileira de Engenharia Agrícola e Ambiental, v.9, suplemento, p.212-216, 2005. 
APHA - American Public Health Association. Standard methods for the examination of water and wastewater. Washington: APHA, 2012. 1190p.

Ayers, R. S.; Westcot, D. W. A qualidade da água na agricultura. Campina Grande: UFPB, 1999. 153p. Estudos FAO: Irrigação e Drenagem, 29

Azevedo, L. P. de.; Oliveira, E. L. de. Efeitos da aplicação de efluente de tratamento de esgoto na fertilidade do solo e produtividade de pepino sob irrigação subsuperficial. Engenharia Agrícola, v.25,p.253-263, 2005.

Bouwer, H.; Chaney, R.L. Land treatment of wastewater. Advances in Agronomy, v.26, p.133-176, 1974.

Cerqueira, L. L.; Fadigas, F. de S.; Pereira, F. A.; Gloaguen, T. V.; Costa, J. A. Desenvolvimento de Heliconia psittacorum e Gladio lushortulanus irrigados com águas residuárias tratadas. Revista Brasileira de Engenharia Agrícola e Ambiental, v.12, p.606-613, 2008.

Christofidis, D. Água na produção de alimentos: O papel da academia e da indústria no alcance do desenvolvimento sustentável. Revista Ciências Exatas, v.12, p.37-46, 2006.

Costa, C. C.; Cecílio Filho, A. B.; Cavarianni, R. L.; Barbosa, J. C. Concentração de potássio na solução nutritiva e a qualidade e número de frutos de melão por planta em hidroponia. Ciência Rural, v.34, p.731-736, 2004.

Costa, M. C. Avaliação dos aspectos sanitários, agronômicos e de qualidade em melancias irrigadas com esgoto tratado. Fortaleza: UFC, 2006. 105p. Dissertação Mestrado

Costa, M. M.; Bonomo, R.; Sena Junior, D. G de.; Gomes Filho, R. R.; Ragagnin, V. A. Produção do maracujazeiro amarelo em condições de sequeiro e irrigado em Jataí - GO. Revista Brasileira de Agricultura Irrigada, v.3, p.13-21, 2009.

Deon, M. D.; Gomes, T. M.; Melfi, A. J.; Montes, C. R.; Silva . E. da. Produtividade e qualidade da cana-de-açúcar irrigada com efluente de estação de tratamento de esgoto. Pesquisa Agropecuária Brasileira, v.45, p.1149-1156, 2010.

Emongor, V. E.;Khonga, E. B.; Ramolemana, G. M.; Marumo, K.;Machacha, S.; Motsamai, T. Suitability of secondary sewage effluent for irrigation of horticultural crops in Botswana. Journal of Applied Sciences, v.5, p.451-454, 2005.

Feitosa, T.; Garruti, D. dos S.; Lima, J. R.; Mota, S.; Bezerra, F. M. L.; Aquino, B. F de.; Santos, A. B dos.; Qualidade de frutos de melancia produzidos com reúso de água de esgoto doméstico tratado. Revista Tecnologia, v.30, p.53-60, 2009.

Florêncio, L.; Aisse, M. M.;Bastos, R. K. X.; Piveli, R. P. Utilização de esgotos sanitários - Marcos conceituais e regulatórios. In: Florêncio, L.; Bastos, R. K. X.; Aisse, M. M. (ed.) Tratamento e utilização de esgotos sanitários. Rio de Janeiro: ABES, 2006. Cap. 1, p.1-15.

Hespanhol, I. Potencial de reúso de água no Brasil: Agricultura, indústria, municípios, recarga de aqüíferos. Bahia Análise \& Dados, v.13, p.411-437, 2003.
Johns, G. G.; McConchie, D. M. Irrigation of bananas with secondary treated sewage effluent. II. Effect on plant nutrients, additional elements and pesticide residues in plants, soil and leachate using drainage lysimeters. Australian Journal of Agricultural Research, v.45, p.1619$1638,1994$.

Lingle, S. E.; Widenfeld, R. P.; Irvine, J. E. Sugarcane response to saline irrigation water. Journal of Plant Nutrition, v.23, p.469-486, 2000.

Medeiros, S. de S.; Soares, F. A. L.; Gheyi, H. R.; Fernandes, P. D. Uso de água residuária de origem urbana no cultivo de gérberas: Efeito nos componentes de produção. Engenharia Agrícola, v.27, p.569-578, 2007.

Miller, G. L. Use of dinitrosalicyclle acid for determination of reducing sugar. Analytical Chemistry,v.11, p.426-428, 1959.

Mota, S.; Bezerra, F. C.; Tomé, L. M. Avaliação do desempenho de culturas irrigadas com esgoto tratado. In: $19^{\circ}$ Congresso Brasileiro de Engenharia Sanitária e Ambiental, 19 1997, Foz do Iguaçu. Anais.... Foz do Iguaçu: SBEA, 1997. CD-Rom

Peres, M. R. Uso de água residuária com diferentes sistemas de irrigação no desenvolvimento e na qualidade microbiológica do meloeiro (Cucumis melo L.). Botucatu: Universidade Estadual Paulista "Júlio de Mesquita Filho", 2004. 50p. Dissertação Mestrado

Raij, B. van; Andrade, J. C. de; Cantarella, H; Quaggio, J. A. Análise química para Avaliação da fertilidade de solos tropicais. Campinas: Instituto Agronômico, $2001.285 \mathrm{p}$.

Ramos, S. R. R.; Lima, N. R. R.; Anjos, J. L dos.; Carvalho, H. W. L de.; Oliveira,I. I. R de.; Sobral, L. F.; Curado, F. F. Aspectos técnicos do cultivo de abóbora na região nordeste do Brasil. Aracaju: Embrapa Tabuleiros Costeiros, 2010. $36 \mathrm{p}$.

Rebouças, J. R. L.; Dias, N. da S.; Gonzaga, M. I. da S.; Gheyi, H. R.;Sousa Neto, O. N. de. Crescimento do feijão caupi irrigado com água residuária de esgoto doméstico tratado. Revista Caatinga, v.23, p.97-102, 2010.

Rego, J. de L.; Oliveira, Oliveira, E. L. L. de .; Chaves, A. F.; Araujo, A. P. B.; Bezerra, F. M. L.; Santos, A. B. dos.; Mota, S. Revista Brasileira de Engenharia Agrícola e Ambiental,v.9,p.155-159, 2005.

Santos, K. D.; Henrique, I. N.; Sousa, J. T. de Duarte, V. L. Utilização de esgoto tratado na fertirrigação agrícola. Revista de Biologia e Ciências da Terra, v.1, p.1-8, 2006.

Sousa, J. T de.; Ceballos, B. S. O. de.; Henrique, I. N.; Dantas, J. P.; Lima, S. M. Reuso de água residuária na produção de pimentão. Revista Brasileira de Engenharia Agrícola e Ambiental, v.10, p.89-96, 2006.

Zenebon, O.; Pascuet, N. S.; Tiglea, P. Métodos físico-químicos para análise de alimentos. São Paulo: Instituto Adolfo Lutz, 2008. 1020p. 